\title{
Electrochemical Characterisation of Polypyrrole Doped with p-Sulfonatocalix[4]arene
}

\author{
Richard Doyle,* Carmel B. Breslin, Orla Power, A. Denise Rooney \\ Department of Chemistry, National University of Ireland Maynooth, Maynooth, County Kildare, Ireland \\ *e-mail: rdoyle5@tcd.ie
}

Received: August 21, 2011

Accepted: November 21, 2011

\begin{abstract}
Polypyrrole (PPy) films doped with macrocyclic calixarene anions are attractive materials for the development of selective sensor materials and membrane systems as the incorporation of the macrocycles can confer specific recognition sites within the polymer matrix. However, unlike many other PPy films a calixarene-doped system is more complicated as calixarenes are themselves electroactive. Here we present results on the electroactivity, impedance properties and morphology of polypyrrole doped with $p$-sulfonatocalix[4]arene. The calixarene in the polymer was found to be irreversibly oxidised at potentials greater than $0.500 \mathrm{~V}$ vs. SCE and reacted to form a new redox active species that was trapped within the polymer matrix. The results from the impedance and EQCM studies indicated that the calixarene was permanently trapped within the polymer matrix and the polymer acted as a cation exchange material. In addition, the data acquired from the EQCM experiments showed that while the material displayed simple cation exchange properties at high scan rates, at lower scan rates the transport of neutral species was also observed. Overall, our findings indicate that the PPy-C4S system is suitable for use as a stable conducting polymer doped with an immobile anion within the potential window of $-0.800 \mathrm{~V}$ to $0.500 \mathrm{~V}$ vs. SCE.
\end{abstract}

Keywords: Sulfonated calixarene, Polypyrrole, Cation exchange material, EQCM, Electrochemical impedance spectroscopy

DOI: 10.1002/elan.201100458

\section{Introduction}

Calixarenes are a class of organic macrocycles consisting of a cyclical array of phenol units linked by short aliphatic bridges. This annular structure forms a hydrophobic cavity that can complex smaller molecules and ions. On account of these recognition properties, calixarenes have found applications in a range of fields such as asymmetric catalysis [1], chromatography [2], analysis of medicinal compounds [3], membrane transport systems [4] and as extractants of radioactive metal cations [5].

The sulfonated calixarenes (Figure 1) are an example of calixarenes which are water soluble and have the ability to bind with a wide range of metal cations, organic ammonium cations and neutral organic molecules [6]. This diverse supramolecular chemistry has led to their application in several fields including pharmaceutical chemistry [7], catalysis [8] and sensors [9]. In particular, the anionic nature of these supramolecules enables their facile incorporation into conducting polymers such as polyaniline [10], poly(3,4-ethylenedioxythiophene) (PEDOT) [11] and polypyrrole (PPy) [12]. Bidan and Niel [12] were the first to incorporate $p$-sulfonatocalix[4]arene (C4S) and $p$ sulfonato-calix[6]arene (C6S) into a PPy film during the electropolymerization process. Notably, upon inspection of the cyclic voltammograms recorded for these films, they proposed that the calixarenes were irreversibly in- corporated into the polypyrrole matrix. Indeed, recent $a c$ electrogravimetry studies performed by Kim et al. [13] have confirmed this conclusion for a PPy-C6S system. They found that the redox switching of a PPy-C6S film was accompanied by the movement of cations, indicating that C6S was immobilised within the PPy matrix. In addition, Bidan and Niel [12] showed that the calixarene retained its inclusion properties when immobilized in the polymer film. These findings are significant as they have led a number of researchers to attempt to exploit the recognition properties of $\mathrm{C} 6 \mathrm{~S}$ and $\mathrm{C} 4 \mathrm{~S}$, when incorporated into conducting polymers, in various sensor and electrochemically controlled membrane applications.

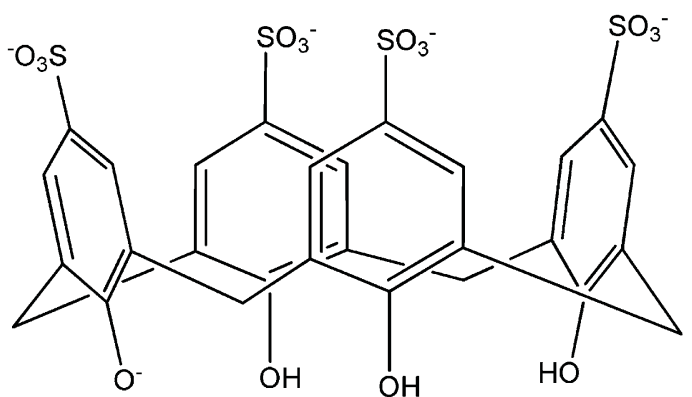

Fig. 1. Structure of the $p$-sulfonatocalix[4]arene anion. 
The first sulfonated calixarene doped conducting polymer modified electrodes investigated as electrochemical sensors were PPy-C4S and PPy-C6S based systems. It was observed that the oxidation peak of the trimethyl(ferrocenylmethyl)ammonium $\left(\mathrm{FcTMA}^{+}\right)$cation showed a significant cathodic shift at the surface of these electrodes [12]. Such a cathodic shift in the redox couple is consistent with complexation of FcTMA ${ }^{+}$by the calixarene [14] and significantly, no such shift was observed when the electrochemistry of $\mathrm{FcTMA}^{+}$was investigated at a PPy film doped with polystyrene sulfonate (PSS). Subsequently, the PPy-C6S system was found to have the ability to electrochemically recognise and immobilise uranyl ions [15]. Studies by Bobacka and co-workers showed that PEDOT doped with C4S could act as an electrochemical sensor for a range of quaternary ammonium cations and showed high selectivity for the pyridinium ion [16]. This modified electrode was also shown to have a high sensitivity for $\mathrm{Ag}^{+}$ions. Following this result, Bobacka then compared both PEDOT and PPy systems doped with C4S, C6S and $p$-sulfonatocalix[8]arene (C8S) and found that all these films showed high selectivity and sensitivity for the $\mathrm{Ag}^{+}$ ion over other metal cations in solution [11]. Furthermore, they showed that silver accumulated within the polymers to a much greater degree than potassium. In addition to these studies, we have shown previously that a PPy-C4S system can act as a highly selective sensor for dopamine. Strikingly, no signal was detected for the common interferent ascorbic acid at this modified electrode, even when it was present in a large excess [17].

Another well studied application of conducting polymers is as electrochemically controlled membranes for the separation of ions between two solutions $[18,19]$. These systems could potentially be employed for water softening and the remediation of metal cation pollutants from water. Recently, Akieh et al. reported a cation exchange membrane based on a PPy-C6S film [20]. While the authors were not successful in making the membrane switchable the use of calixarenes in these systems is interesting as they can be tailored to recognise specific cations.

In addition to the above studies, an investigation on polyanaline doped with $\mathrm{C} 4 \mathrm{~S}$ or $\mathrm{C} 6 \mathrm{~S}$ colloidal suspensions showed that the colloids were electroactive and had enhanced stability towards alkaline dedoping compared to polyaniline formed using other dopants [10].

Although there has been much interest in the possible applications of $p$-sulfonatocalixarene doped conducting polymers, with the notable exception of the recent study on the PPy-C6S system [13], the electrochemical properties of these films, their stability and redox behaviour in particular, have received little attention in the literature. This is surprising considering the known electroactivity of the sulfonated calixarenes. Diao et al. and Pailleret et al. reported the irreversible oxidation of these calixarenes at potentials greater than $0.7 \mathrm{~V}$ vs. SCE [21-25]. In particular, Diao et al. determined that the oxidation of $\mathrm{C} 4 \mathrm{~S}$ was an irreversible two-electron transfer reaction [23]. It is

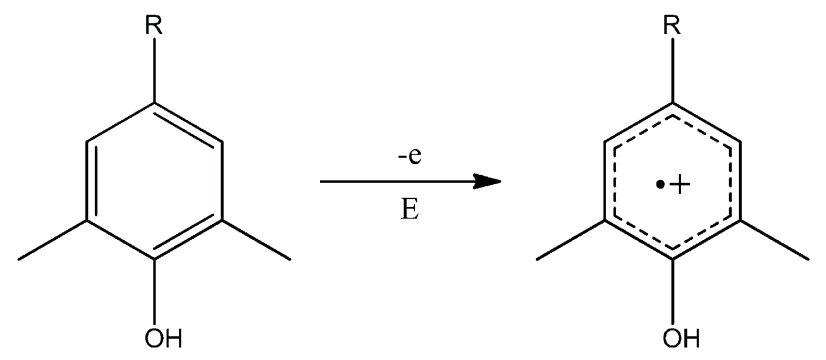

Phenol moiety of Calixarene
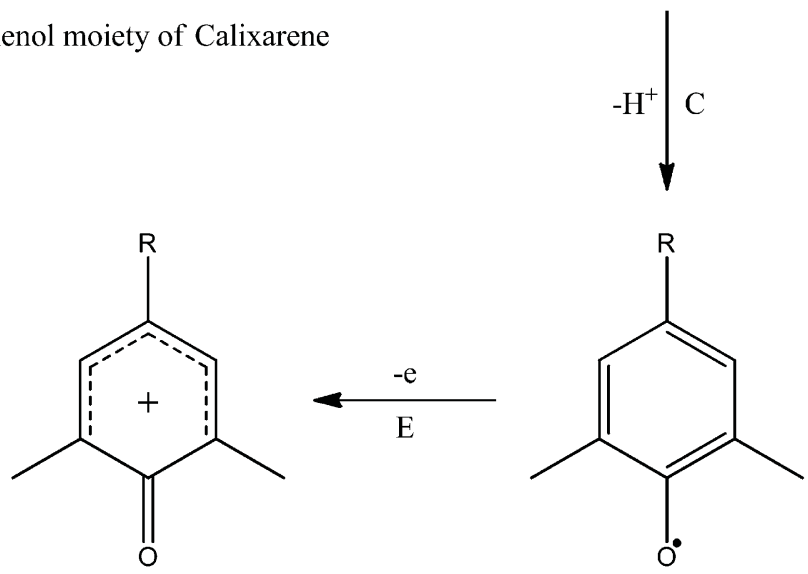

Phenoxylium cation

Scheme 1. The oxidation mechanism for the phenol moieties of a calixarene [26].

likely that this 2-electron oxidation process results in the formation of a reactive phenoxylium cation by the ECE mechanism shown in Scheme 1, as proposed for other calixarene systems [26]. Therefore, it is reasonable to expect that this electroactivity, depending on the potentials applied to the polymer film, can have a significant effect on the voltammetric behaviour and stability of the film.

In some situations, for example the use of calixquinones in redox dependant ionophores (RDI), the electroactivity of the calixarene can be advantageous. In these systems, complexation of a specific ion results in a change in the electrochemical response of the calixarene. [27] However, in cases where the calixarene is employed purely based on its recognition properties and the redox response of the calixarene is non reversible, such as in C4S and C6S doped conducting polymer modified electrode based sensors, the electroactivity of the calixarene can be a complication and needs to be avoided.

Therefore, in this paper we present a study on the electrochemical activity, impedance properties and morphology of a PPy film doped with C4S.

\section{Experimental}

Pyrrole (98\%), $\mathrm{Na}_{2} \mathrm{SO}_{4}(\geq 99.0 \%$ ) were purchased from Sigma-Aldrich. Pyrrole was distilled under vacuum and stored under nitrogen in the dark at $-20^{\circ} \mathrm{C}$. $p$-sulfonatocalix[4]arene was synthesised using the methods outlined 
by Shinkai et al. [28]. Aqueous solutions were prepared using water which was distilled and Milli-Q purified in the laboratory (14 $\mathrm{M} \Omega \mathrm{cm}, \mathrm{pH} 5.0)$.

A standard three electrode cell was used for all electrochemical experiments. With the exception of the EQCM studies, the working electrode was a platinum disk electrode with a surface area of $0.1257 \mathrm{~cm}^{2}$. Prior to each experiment the working electrode was polished with 30,15 , 6 and $1 \mu \mathrm{m}$ diamond suspensions (Buehler), sonicated and rinsed with distilled water. The reference electrode was a saturated calomel electrode (SCE) and the counter electrode was a $1 \mathrm{~mm}$ diameter platinum wire. Unless otherwise stated, the electrolyte used for the electrochemical experiments was a $0.10 \mathrm{moldm}{ }^{-3} \mathrm{Na}_{2} \mathrm{SO}_{4}$ solution.

PPy-C4S films were deposited on a Pt electrode from an aqueous solution containing $0.20 \mathrm{~mol} \mathrm{dm}^{-3}$ pyrrole and $0.01 \mathrm{~mol} \mathrm{dm}^{-3} \mathrm{C} 4 \mathrm{~S}$. The polymer was grown at a constant potential of $0.500 \mathrm{~V}$ vs. SCE until a charge of $0.24 \mathrm{Ccm}^{-2}$ was reached. The electrode was then removed from the polymerization solution and rinsed with distilled water. Any deviations from this method are highlighted in the relevant sections.

Electrochemical quartz crystal microbalance (EQCM) measurements were performed using a potentiostat Chi440 instrument (Model EA160) which was controlled using Chi440 software (version 1.0.0.1). For the EQCM experiments the PPy-C4S films were deposited on a gold electrode with a surface area of $0.2033 \mathrm{~cm}^{2}$. A silver/silver chloride $(\mathrm{Ag} / \mathrm{AgCl})$ electrode $\left(3.0 \mathrm{~mol} \mathrm{dm}^{-3} \mathrm{KCl}\right.$ filling solution) was used as the reference electrode and the polymer was grown at a constant potential of $0.550 \mathrm{~V}$ vs. $\mathrm{Ag} / \mathrm{AgCl}$ to a charge of $0.074 \mathrm{C} \mathrm{cm}^{-2}$.

Scanning electron microscopy (SEM) and energy dispersive X-ray spectroscopy (EDX) were performed using a Hitachi S-4000 with a cold cathode field emission electron source (FE-SEM) equipped with Princeton Gamma Technology Avalon 8000 EDX system with a liquid nitrogen cooled $\mathrm{Li}(\mathrm{Si})$ detector. The samples were sputter coated with gold or gold/palladium ultrathin films with an
AGAR Automatic Sputter Coater. Thickness measurements of the PPy-C4S films were carried out using a KLA Tencor P15 stylus profilometer.

Electrochemical impedance spectroscopy was carried out with a Solartron potentiostat (Model SI 1287) coupled to a Solartron frequency response analyser (Model SI 1255A). EIS spectra were recorded at potentials in the range $-0.800 \mathrm{~V}$ to $0.500 \mathrm{~V}$ vs. SCE for the PPy-C4S film. Before each impedance measurement the film was equilibrated for $30 \mathrm{~min}$ at the applied potential. The frequency response was then recorded between $60 \mathrm{kHz}$ and $10 \mathrm{mHz}$ using a sinusoidal voltage with an amplitude of $10 \mathrm{mV}$. Equivalent electrical circuit modeling was performed using Zplot (Version 2.1).

\section{Results and Discussion}

\subsection{Surface Analysis of the PPy-C4S Film}

Information on the surface morphology of the PPy-C4S film was obtained using SEM. Figure 2 shows SEM micrographs recorded for PPy-C4S films electropolymerized at $0.500 \mathrm{~V}$ and $0.800 \mathrm{~V}$ vs. SCE. These micrographs exhibit the typical 'cauliflower' morphology commonly observed for PPy films. Indeed, Akieh et al. also observed 'cauliflower' morphologies for PPy films doped with C6S [20]. It should also be noted from the SEM micrographs that the film formed at $0.800 \mathrm{~V}$ vs. SCE (Figure 2b) possessed a rougher surface morphology than the film grown at $0.500 \mathrm{~V}$ vs. SCE (Figure 2a). Similar results were reported by Zhu et al. [29] and Reyes et al. [30] who found that PPy films formed at low potentials were more uniform than those formed at higher potentials.

EDX spectra were also recorded for the PPy-C4S films discussed above. These spectra showed a characteristic peak for sulfur $\left(K_{\alpha}=2.3075 \mathrm{keV}\right)$ indicating that $\mathrm{C} 4 \mathrm{~S}$ had been successfully incorporated into the PPy film.
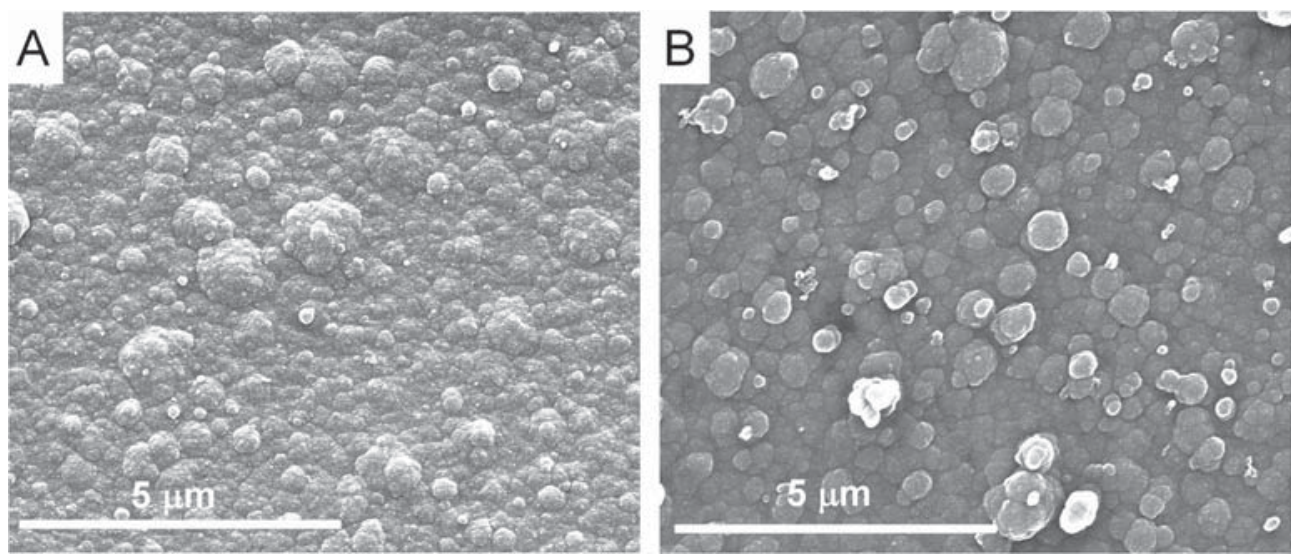

Fig. 2. SEM images of a PPy-C4S film electropolymerized (a) at $0.500 \mathrm{~V}$ vs. SCE and (b) at $0.800 \mathrm{~V}$ vs. SCE on a Pt electrode from a solution containing $0.20 \mathrm{M}$ pyrrole and $0.01 \mathrm{M} \mathrm{C} 4 \mathrm{~S}$ to a charge of $0.24 \mathrm{C} \mathrm{cm}^{-2}$. 


\subsection{Redox Properties of the PPy-C4S Film.}

\subsubsection{Electrochemical Behaviour Associated with the Polymer Matrix}

Cyclic voltammetry was used to study the redox behaviour of the PPy-C4S film. Figure $3 \mathrm{a}$ shows a $\mathrm{CV}$ recorded between $-0.800 \mathrm{~V}$ and $0.200 \mathrm{~V}$ vs. SCE. A single redox couple corresponding to the oxidation $(-0.214 \mathrm{~V}$ vs. SCE) and reduction $(-0.455 \mathrm{~V}$ vs. SCE) of the PPy backbone was observed. The peak separation of $0.241 \mathrm{~V}$ was indicative of a quasi-reversible process which is typical of PPy films. This value is close to the peak separation of approximately $0.23 \mathrm{~V}$ observed by Bidan et al. for their PPy-C4S film [12].

It can be seen from Figure $3 a$ that the reduction peak was sharper than the oxidation peak indicating that the rate of reduction was faster than the rate of oxidation. This is often observed for PPy films doped with large immobile anions [31,32] and is consistent with the proposal of Bidan et al. that $\mathrm{C} 4 \mathrm{~S}$ is irreversibly incorporated into a PPy film [12]. Therefore, as observed by Kim et al. [13] for a PPy-C6S system, reduction of the PPy-C4S film is accompanied by an influx of cations. The sharper appearance of the reduction wave for these films has been attributed to the high mobility of the cations and to the ionic concentration gradient between the bulk electrolyte and the film [33]. During the reduction process cations are able to diffuse into the cation starved film to compensate the charge of the immobilised anions. In contrast, the cations are slow to diffuse out of the film during oxidation due to the high ion content of both the film and the electrolyte. As a result, the reduction of the PPy-C4S film, which involves the incorporation of $\mathrm{Na}^{+}$ions from the solution phase into the film, is a relatively fast and efficient process, whereas oxidation of the polymer is slower due to the slow release of $\mathrm{Na}^{+}$ions. The ion exchange properties of the PPy-C4S film are examined in further detail in Section 3.3.

\subsubsection{Electrochemical Behaviour of C4S Trapped within the Polymer Matrix}

When the voltammetric response of the PPy-C4S film was examined at higher potentials a second redox couple centred at $0.230 \mathrm{~V}$ vs. SCE was observed (Figure 3b). It can be seen from Figure $3 b$ that the redox couple was initially absent but then developed steadily with successive cycling, reaching an eventual steady state. In addition, it was found that the magnitude of this redox couple was strongly dependent on potential. Figure $3 \mathrm{c}$ shows the influence of the upper potential limit on the redox process. Clearly, a threshold potential existed, below which the redox couple could not be generated. A well defined redox couple was only observed when the potential was scanned to $0.800 \mathrm{~V}$ vs. SCE. Moreover, the redox couple was absent when the upper potential limit was $0.500 \mathrm{~V}$ vs. SCE. This type of behaviour was consistent with the for-
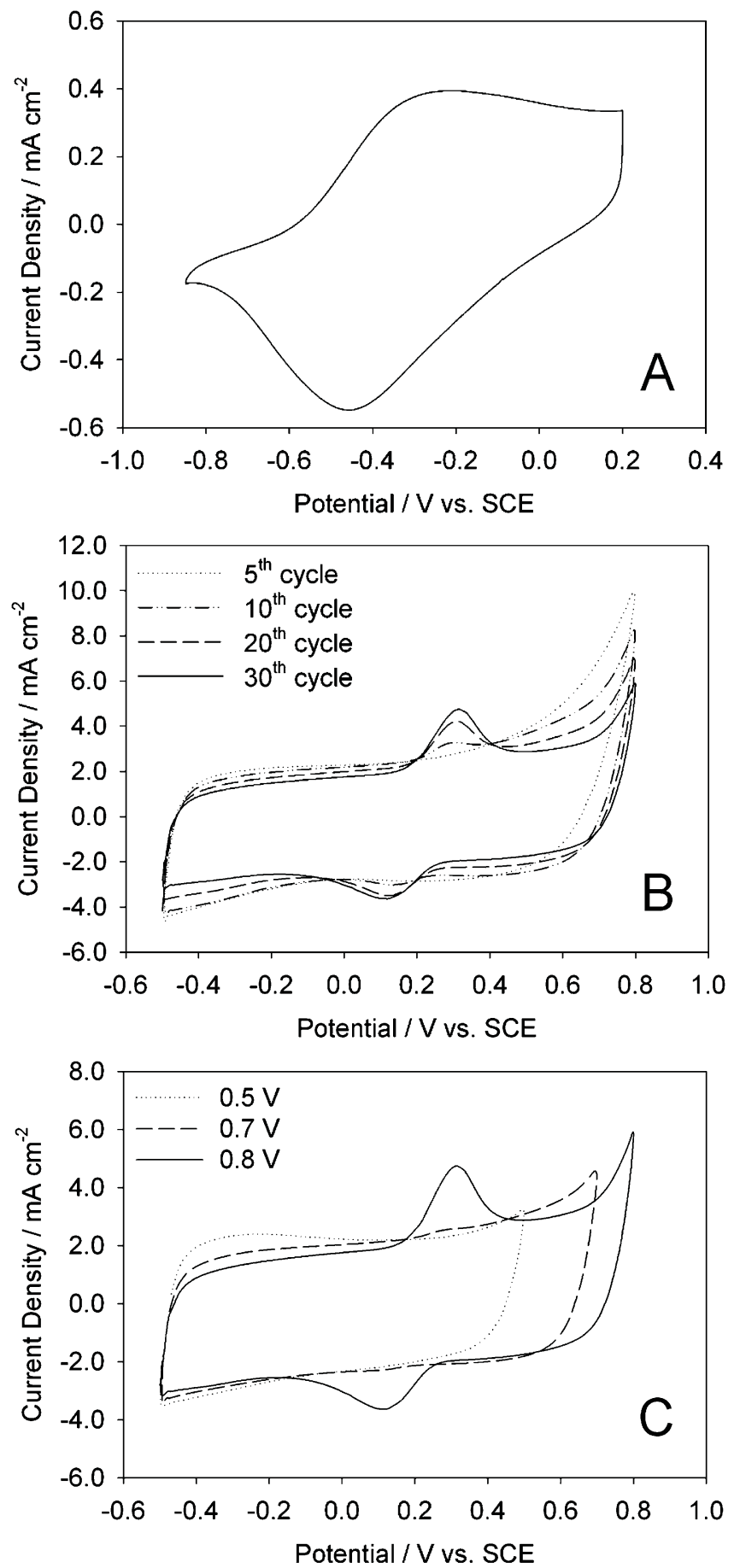

Fig. 3. Cyclic voltammograms for a PPy-C4S film in $0.10 \mathrm{M}$ $\mathrm{Na}_{2} \mathrm{SO}_{4}$ solution. (a) The redox behaviour of the PPy film recorded at a scan rate of $5 \mathrm{mV} \mathrm{s}^{-1}$. (b) The development of the redox couple arising from the species formed in the PPy film with continuous potential cycling and (c) the effect of the upper potential limit on the development of the redox couple arising from the species formed in the PPy film. The $30^{\text {th }}$ cycle is shown for each upper potential.

mation of a new electroactive species within the PPy-C4S film.

When similar experiments were carried out on $\mathrm{PPy}-\mathrm{Cl}$ and $\mathrm{PPy}_{-} \mathrm{SO}_{4}$ films only the expected redox behaviour as- 
sociated with the PPy backbone was observed. This indicated that the redox couple arose from the presence of $\mathrm{C} 4 \mathrm{~S}$ in the film. Interestingly, the threshold potential required to properly observe the PPy-C4S redox couple $(0.800 \mathrm{~V}$ vs. SCE $)$ corresponded with $\mathrm{E}_{1 / 2}$ for the oxidation of C4S $(0.780 \mathrm{~V}$ vs. SCE). To clarify these observations it was necessary to examine the electroactivity of C4S. In accordance with literature results [23], a single oxidation peak at $0.900 \mathrm{~V}$ vs. SCE with no corresponding reduction peak was observed. This confirmed the irreversible oxidation of C4S. However, a small reduction peak was observed on the reverse scan with a corresponding oxidation peak appearing on the ensuing forward scan. Therefore, the oxidation of $\mathrm{C} 4 \mathrm{~S}$ in solution also resulted in the formation of a new species which exhibited a redox couple. Attempts to characterise this species failed as it was formed in such low amounts and it may not be stable. However, even though the peak separation for the redox couple in solution $(0.360 \mathrm{~V})$ is greater than in the polymer $(0.200 \mathrm{~V})$, we would propose that they arise from the same species. Such decreases in peak separation are not uncommon for surface bound species, Raoof et al. reported a $630 \mathrm{mV}$ reduction in peak separation for $\mathrm{Fe}(\mathrm{CN})_{6}^{3-}$ incorporated in a PPy film [34], and can be accounted for by their close proximity to the electrode surface.

A likely redox active product, which could be formed following the oxidation of a calixarene to a phenoxylium cation (Scheme 1), is a quinone. Although the conversion of sulfonated calixarenes to a quinone containing macrocycle has not been reported previously, Louati and coworkers have been able to isolate mono and diquinone species formed electrochemically from calix[4]arenes in dichloromethane solution $[26,35]$. The mechanism proposed for this reaction was similar to that put forward by Ronlan et al. for the synthesis of quinones from sterically hindered phenols [36]. The phenol moieties of the calixarene were oxidised via a two electron ECE mechanism to form a phenoxylium cation as shown in Scheme 1. Louati and co-workers $[26,35]$ found that this species was sus- ceptible to nucleophilic attack from residual water in the organic solvents, resulting in the formation of a quinone (Figure 4). Considering that this mechanism has been applied to a number of different para substituted calix[4]arenes, it is reasonable to apply it to C4S. Especially, since the oxidation of $\mathrm{C} 4 \mathrm{~S}$ involves the transfer of two electrons and the solvent used in this work was water itself, which would make the nucleophilic substitution reaction more favorable.

Even though the new redox active species was not characterised the fact that the calixarene can be oxidised within the film at potentials similar to that observed in solution and can form reactive radical and cationic species has implications for the use of these systems. For example, we have previously applied the PPy-C4S system to the sensing of dopamine [17]. During the course of that study we investigated the influence of the polymerization conditions on the stability of the sensor. It was observed using cyclic voltammetry that the peak current for dopamine decreased by $30 \%$ after 20 cycles when the polymer was grown at potentials greater than $0.500 \mathrm{~V}$ vs. SCE and this decrease would continue with subsequent cycling. Conversely, when the polymer was prepared at $0.500 \mathrm{~V}$ vs. SCE or less a more stable signal was obtained, with only a $5 \%$ decrease in intensity over the first 20 cycles and thereafter reaching a steady state [37]. Furthermore, the electrochemistry of the calixarene does not just influence the potential at which the PPy-C4S film can be formed, it also limits the upper potential value that can be applied to the polymer. As can be observed from Figure $3 \mathrm{~b}$, when the polymer was cycled up to $0.800 \mathrm{~V}$ vs. $\mathrm{SCE}$, in addition to the growth of the new redox couple, the background current decreased steadily with each cycle. This decrease became more pronounced with continued cycling and indicated a loss in the conductivity of the film. These findings are in contrast with those acquired when we employed polypyrrole doped with a sulfonated $\beta$-cyclodextrin (which is not easily oxidized). A stable film was obtained when the polymer was electrosynthesized at $0.800 \mathrm{~V}$ vs. SCE and when the film was em-

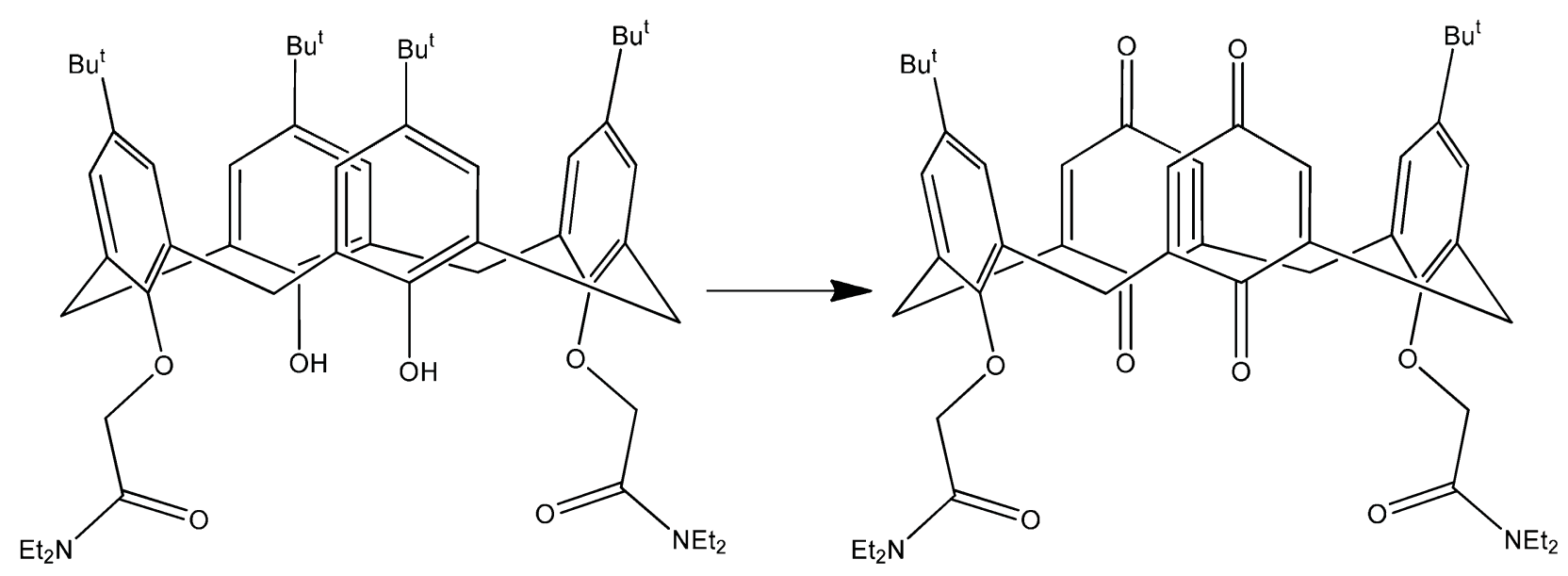

Fig. 4. p-tert-butylcalix[4]arene- $(\mathrm{OH})_{2}-\left(\mathrm{OCH}_{2} \mathrm{CONEt}_{2}\right)_{2}$ and the calixdiquinone synthesised from it $[26,35]$. 
ployed as an electrochemical sensor for dopamine reproducible cyclic voltammograms could be recorded up to potentials of $0.900 \mathrm{~V}$ vs. SCE [38].

\subsection{Investigation of the Ion Exchange Behaviour of the PPy-C4S Films Studied Using EQCM}

\subsubsection{Electropolymerization}

The polymer was deposited on a gold electrode at a potential of $0.550 \mathrm{~V}$ vs. $\mathrm{Ag} / \mathrm{AgCl}$ to a charge of $0.074 \mathrm{Ccm}^{-2}$. The relationship between the change in the oscillator frequency of the crystal and the change in mass is given by the Sauerbrey equation (Equation 1)

$\Delta f=-C_{f} \Delta m$

Where $\Delta f$ is the change in the frequency, $\Delta m$ is the change in mass per unit area and $C_{f}$ is the sensitivity factor of the crystal. The Sauerbrey equation can only be applied if the PPy film is thin (less than $500 \mathrm{~nm}$ in thickness), uniform and rigid [39-41]. When PPy films fulfil these requirements there is a linear relationship between the change of mass of the crystal and the charge consumed during the deposition of the polymer. The PPyC4S film grown for the EQCM experiments did fulfil these requirements. A plot of the change in mass against charge for the deposition of the PPy-C4S film was determined to be linear. Moreover, Tencor profilometry measurements on PPy-C4S films grown to a charge of $0.08 \mathrm{Ccm}^{-2}$ showed that the thickness of these films was approximately $250 \mathrm{~nm}$. Therefore, it is reasonable to assume that the films grown to a charge of $0.074 \mathrm{Ccm}^{-2}$ for the EQCM experiments are sufficiently thin.

\subsubsection{Massogram and Cyclic Voltammogram of PPy-C4S in $\mathrm{NaCl}$ Solution the Effect of Scan Rate}

Three separate PPy-C4S films were cycled in a $0.10 \mathrm{~mol} \mathrm{dm}^{-3} \mathrm{NaCl}$ solution at scan rates of 10,50 and $100 \mathrm{mV} \mathrm{s}^{-1}$, and the mass change and current response were recorded as a function of potential. The resulting massograms and cyclic voltammograms for the $5^{\text {th }}$ cycle are shown in Figure 5. As would be expected the size of the anodic and cathodic peak currents for the PPy-C4S film decreased as a function of scan rate. The shape of the massograms for the three scan rates are generally similar and are typical for PPy doped with an immobile anion [39]. Initially, upon reducing the potential from $0.100 \mathrm{~V}$ to approx. $-0.400 \mathrm{~V}$ vs. $\mathrm{Ag} / \mathrm{AgCl}$, the mass of the film decreased steadily. This is consistent with the expulsion of mobile $\mathrm{Cl}^{-}$ions which had been absorbed into the polymer from the electrolyte solution.

However, when the potential reached a value in the region of -0.400 to $-0.500 \mathrm{~V}$ vs. $\mathrm{Ag} / \mathrm{AgCl}$, at which point the PPy backbone was significantly reduced, the mass of the polymers started to increase and continued to increase as the polymers were further reduced to $-0.800 \mathrm{~V}$ vs. $\mathrm{Ag} / \mathrm{AgCl}$. During this potential window it would be expected that the $\mathrm{Na}^{+}$ions from the electrolyte solution would influx into the polymers to balance the charge on the immobile anionic calixarene dopants. Subsequently, as the potential was cycled back in the anodic direction, each polymer was observed to lose mass, corresponding to the efflux of $\mathrm{Na}^{+}$ions, until potentials of -0.100 or $-0.200 \mathrm{~V}$ vs. $\mathrm{Ag} / \mathrm{AgCl}$, where the polymers were fully oxidised, were reached. When the polymers were cycled above this potential region they started to increase in mass again corresponding to the influx of $\mathrm{Cl}^{-}$ions from the electrolyte.

A quantitative analysis of the data acquired from the EQCM experiments was then carried out by relating the change in mass of the polymer to the total amount of charge passed using Faraday's law (Equation 2)

$\Delta m=M^{\prime} Q / z F$

Where $\Delta m$ is the change in mass of the polymer recorded during the EQCM experiment, $M^{\prime}$ is the apparent molar mass of the species moving into or out of the polymer and causing the change in mass, $F$ is Faraday's constant, $z$ is the charge on the ion which is being transferred and $Q$ is the charge consumed during the reaction. Upon carrying out this analysis, differences in the behaviour of the polymers as a function of the potential scan rate became apparent. In particular, linear regions were observed on the reductive scan in the plots of $\Delta m / Q$ in the region of $(-0.645$ to $-0.827 \mathrm{~V}),(-0.609$ to $-0.823 \mathrm{~V})$ and $(-0.578$ to $-0.832 \mathrm{~V})$ for the polymers cycled at 100,50 and $10 \mathrm{mV} \mathrm{s}^{-1}$, respectively. Using equation (2), the apparent molar mass of the species moving into each of the three polymers was determined to be 38.92, 21.97 and $11.81 \mathrm{~g} \mathrm{~mol}^{-1}$. If the only process occurring at this stage of the redox cycle was the movement of $\mathrm{Na}^{+}$ions the apparent molar mass would be $22.99 \mathrm{~g} \mathrm{~mol}^{-1}$. While the apparent molar mass calculated at $100 \mathrm{mV} \mathrm{s}^{-1}$ was greater than the theoretical value, it is believed that this can be accounted for by the fact that the $\mathrm{Na}^{+}$ions will be solvated. It is well established that the influx of cations into a polymer is accompanied by solvent uptake [42]. Indeed, Akieh et al. [39] have also observed mass changes greater than the theoretical values for a PPy-PSS film. They too attributted these elevated values to the influx of solvent molecules. Interestingly, at the slowest scan rate the apparent molar mass is lower than the molar mass of $\mathrm{Na}^{+}$. The most likely explanation for this observation was that at this scan rate, in addition to the movement of $\mathrm{Na}^{+}$ions into the polymer, there was also the movement of neutral species (salt or water) out of the polymer. This is consistent with observations in the literature for PPy doped with the immobile polystyrene sulfonate anion (PSS) [39]. In that work, it was proposed that the reduction in the apparent molar mass of the influxing species upon reduction of the potential scan rate arises due to increased movement of neutral species. At higher scan rates the movement of ions is kinetically favoured whereas at 

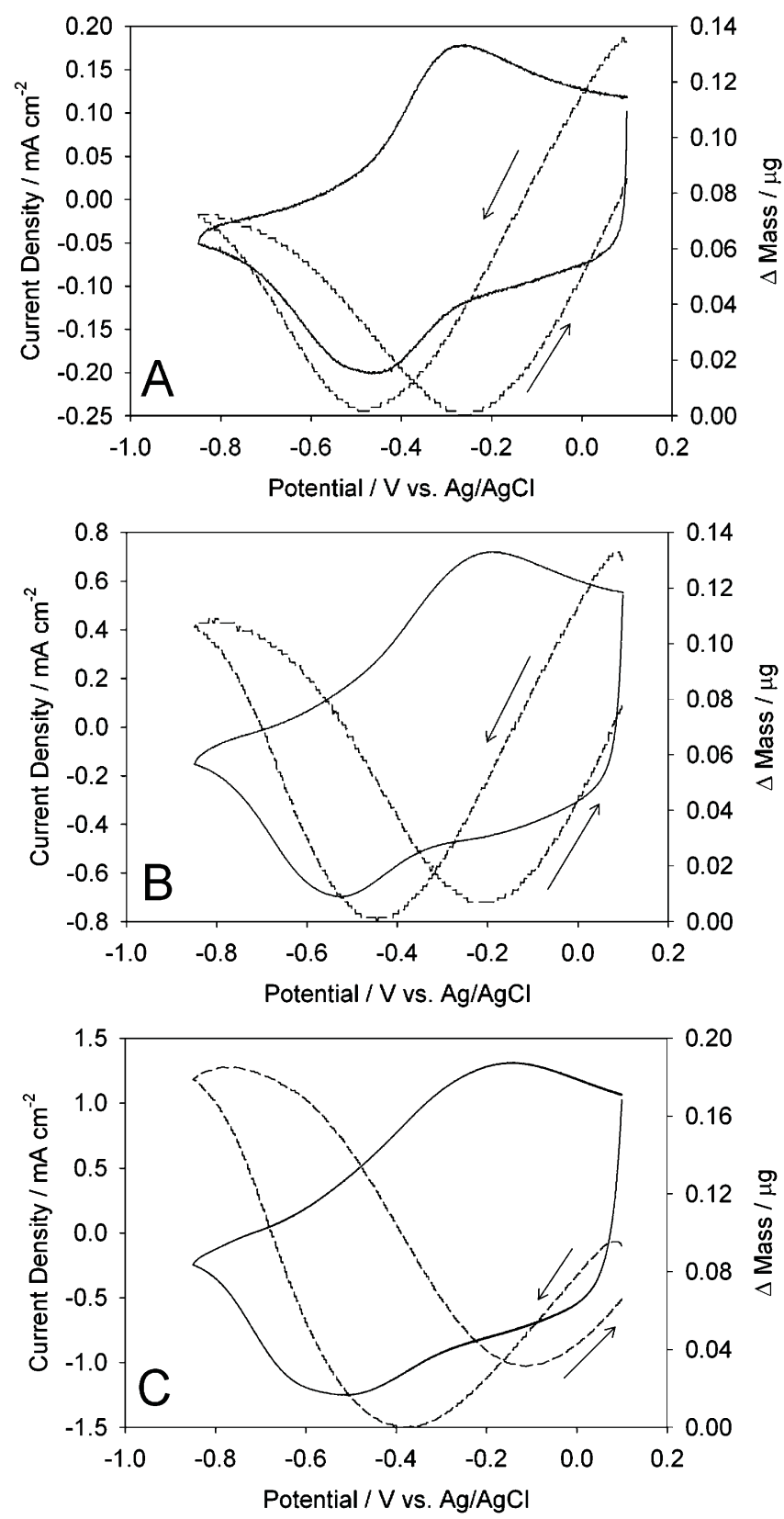

Fig. 5. The $5^{\text {th }}$ scan of cyclic voltammograms (-) and massograms (---) associated with the oxidation and reduction of PPyC4S films in a $0.10 \mathrm{~mol} \mathrm{dm}^{-3} \mathrm{NaCl}$ solution at scan rates of a) 10 b) 50 and c) $100 \mathrm{mV} \mathrm{s}^{-1}$.

lower scan rates the movement of neutral species becomes more significant and competes with the movement of ions. It would appear that a similar effect was occurring for the PPy-C4S system studied here.

\subsection{Electrochemical Impedance Spectroscopy}

Electrochemical impedance spectroscopy was used to study the electrical properties of the PPy-C4S film. The impedance of a PPy film is classically interpreted using a dual rail transmission line in which the motion of electrons along the polymer chains is described by one resist- ance rail $\left(R_{\mathrm{e}}\right)$, while the motion of the counterions in the pores is described by a second resistance rail $\left(R_{\text {ion }}\right)$. A distributed capacitance connects the two rails and models the faradaic capacitance $\left(C_{\mathrm{f}}\right)$ of the polymer $[43,44]$. To the best of our knowledge this is the first electrochemical impedance study of PPy doped with a sulfonated calixarene.

The frequency response of the PPy-C4S film was recorded over a range of potentials from $-0.800 \mathrm{~V}$ to $0.500 \mathrm{~V}$ vs. SCE. This potential range encompassed both the oxidised and reduced forms of the film and the complex plane impedance plots exhibited two forms depending on the degree of oxidation of the film. Typical complex plane impedance plots recorded between $-0.400 \mathrm{~V}$ and $0.500 \mathrm{~V}$ vs. SCE, where the PPy-C4S film was largely in the oxidised state, are shown in Figure 6a while the plots obtained at $-0.600 \mathrm{~V}$ and $-0.800 \mathrm{~V}$ vs. SCE, where the film was predominantly in the reduced state, are shown in Figure 6b. The corresponding equivalent circuits are given in Figure $6 \mathrm{c}$ and Figure 6d respectively, and the resistance and capacitance values determined for the PPy-C4S film using these circuits are also presented. The quality of the fit can be seen from the close agreement between the experimental and simulated impedance plots with the average $\chi^{2}$ value being $3.1 \times 10^{-4}$.

The resistor $R_{\mathrm{s}}$ represented the resistance of the electrolyte solution. The parallel combination of a constant phase element $\left(\mathrm{CPE}_{\mathrm{p}}\right)$ and a resistor $\left(\mathrm{R}_{\mathrm{p}}\right)$ represented the pseudo-capacitance and resistance of the polymer film, respectively. Warburg behaviour $\left(\mathrm{W}_{\mathrm{i}}\right)$, as it applies to conducting polymers, has been attributed to the slow motion of ions within a porous polymer film [45]. In this case, $W_{\mathrm{i}}$ describes the movement of $\mathrm{Na}^{+}$or $\mathrm{SO}_{4}{ }^{2-}$ ions in the PPyC4S film (see Section 3.3). The emergence of a high-frequency semicircle for the reduced films (Figure 6b) suggests that an interfacial charge-transfer process is now sufficiently slow to be observed. A similar effect was found by Ren and Pickup [46] and they attributed this observation to electron transfer at the polymer-electrode interface. They computed a double-layer capacitance of $28 \mu \mathrm{F} \mathrm{cm}^{-2}$, which is close to the capacitance of a bare electrode. Although the $\mathrm{CPE}_{\text {int }}$ was computed as $9.5 \times$ $10^{-5} \Omega^{-1} \mathrm{~s}^{0.67}$ for the reduced film polarized at $-0.800 \mathrm{~V}$ vs. SCE, the exponent of the CPE element is 0.67, which makes it difficult to extract the true double-layer capacitance. Therefore, this high-frequency semicircle may indeed be connected with electron transfer at the polymer-electrode interface.

\subsubsection{Resistance of the PPy-C4S Film}

It is clear from Figure 6 that the resistance of the oxidised PPy-C4S film $\left(\mathrm{R}_{\mathrm{p}}\right)$ decreased as the potential was lowered from $0.500 \mathrm{~V}$ to $-0.400 \mathrm{~V}$ vs. SCE. This form of relationship between the resistance and potential is characteristic of a cation exchange polymer. Ren and Pickup [46,47] carried out detailed studies of both ion and electron transport in the cation exchange polymer PPy-polystyrene 

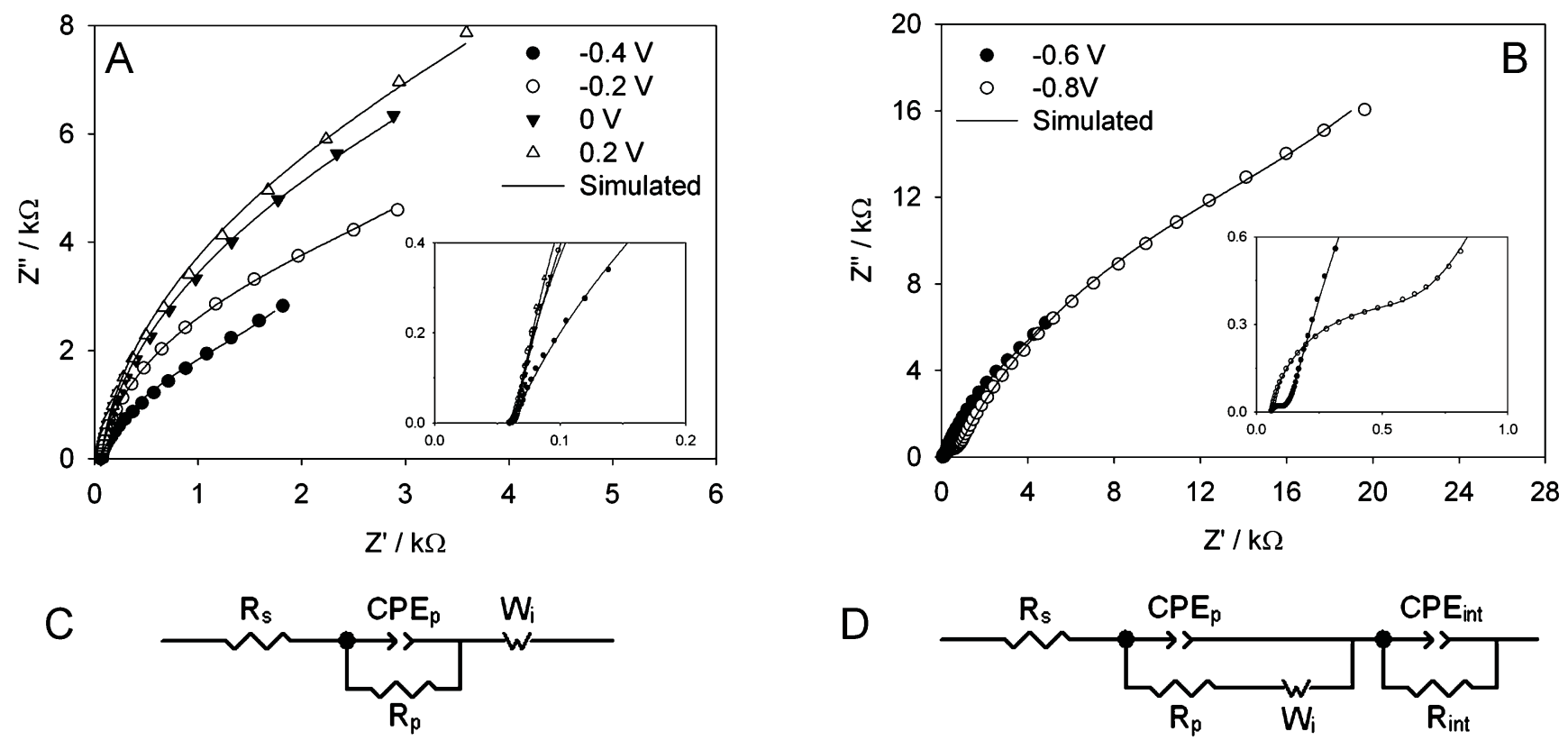

\begin{tabular}{ccc}
\hline $\mathrm{E} / \mathrm{V}$ & $\begin{array}{c}\mathrm{CPE}_{\mathrm{p}} / \\
\Omega^{-1} \mathrm{~s}^{\mathrm{n}}\end{array}$ & $\mathrm{R}_{\mathrm{p}} / \Omega$ \\
\hline 0.5 & 9.5 & 8145 \\
0.3 & 9.5 & 7369 \\
0.2 & 11.1 & 7773 \\
0.0 & 13.5 & 7228 \\
-0.2 & 17.5 & 3653 \\
-0.3 & 19.9 & 2516 \\
-0.4 & 19.0 & 1873 \\
-0.6 & 6.4 & 9612 \\
-0.8 & 1.3 & 23053 \\
\hline
\end{tabular}

Fig. 6. Experimental and simulated impedance data for the PPy-C4S film in (a) the predominantly oxidised state and (b) the reduced state along with the corresponding equivalent circuits (c) and (d) respectively. The $\mathrm{CPE}_{\mathrm{p}}$ and $R_{\mathrm{p}}$ values determined from the circuit fitting results are presented in tabulated form. Note: the exponent of the $\mathrm{CPE}_{\mathrm{p}}, n=0.91 \pm 0.02$.

sulfonate (PPy-PSS). In particular, they found that the electrochemical impedance of oxidised PPy-PSS films could be described using a single resistance rail representing $R_{\text {ion }}$, due to the high electronic conductivity of PPy in the oxidised state [47]. This resistance was found to decrease with potential which can be explained as follows. The ionic resistance is governed by the concentration of mobile charge carriers in the film. In the oxidised state, the electroneutrality of the film is maintained by the immobile counteranion (C4S or PSS). As such, there is a lack of mobile ionic charge carriers in the film and a high ionic resistance. As the potential is lowered, the film begins to be reduced and $\mathrm{Na}^{+}$cations enter the film to balance the negative charges on the calixarene. This results in an increase in the concentration of mobile charge carriers in the film and a decrease in the ionic resistance. In this way, the results outlined here can be regarded as further evidence that $\mathrm{C} 4 \mathrm{~S}$ is irreversibly incorporated into the polypyrrole matrix.

When the potential was lowered below $-0.400 \mathrm{~V}$ vs. SCE a dramatic increase in $R_{\mathrm{p}}$ was observed (Figure 6).
This was consistent with the increasing electronic resistance of the PPy-C4S film in this potential range. Ren and Pickup observed a similar trend for PPy-PSS films [46]. At high reduction potentials, they found that the ionic resistance reached a constant minimum value while the electronic resistance increased significantly. In fact, they showed that the impedance of a reduced PPy-PSS film could be adequately described using a single resistance rail $\left(R_{\mathrm{e}}\right)$. Notably, the values they obtained for $R_{\mathrm{e}}$ (approx $10 \mathrm{k} \Omega$ ) are comparable to the $R_{\mathrm{p}}$ values reported here for the reduced PPy-C4S film. As such, the increase in $R_{\mathrm{p}}$ with decreasing potential was in accordance with the increased reduction of the film.

\subsubsection{Capacitance Measurements for the PPy-C4S Film}

The faradaic capacitance $\left(C_{\mathrm{f}}\right)$ of the PPy-C4S film was obtained directly from the impedance data by plotting the imaginary impedance $\left(Z^{\prime \prime}\right)$ as a function of $1 / \omega$. The plots obtained at all potentials were linear at intermediate frequencies with slope $=1 / C_{f}$, as shown in the inset of 

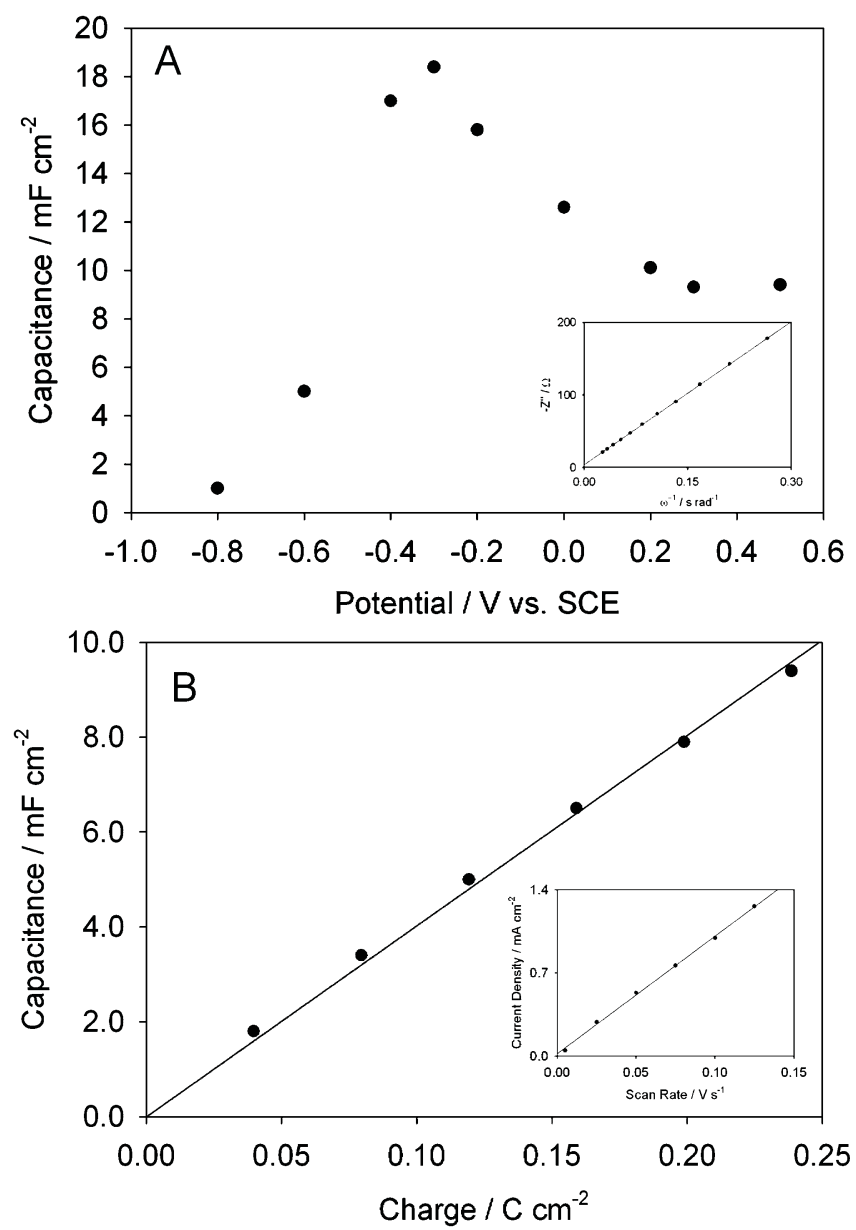

Fig. 7. (a) The capacitance of the PPy-C4S film obtained from the impedance data as a function of potential. Inset: $Z^{\prime \prime}$ vs. $1 / \omega$, the inverse slope gives the capacitance. (b) CV capacitance measurements as a function of charge. Inset: $I$ vs. scan rate, the capacitance is given by the slope.

Figure 7a. It should be noted that the $C_{\mathrm{f}}$ values obtained in this manner are in good agreement with the $\mathrm{CPE}_{\mathrm{p}}$ values obtained from the equivalent circuit fitting (Figure 6), indicating that the value of the $\mathrm{CPE}_{\mathrm{p}}$ element is a good approximation of the capacitance of the polymer. The relationship between $C_{\mathrm{f}}$ and potential is illustrated in Figure 7a. The capacitance of the film is lowest in the reduced state. As the potential increases and the film is oxidised the capacitance also increases reaching a maximum near the peak oxidation potential of the film. This observation was consistent with the idea that the capacitance of a PPy film is related to its faradaic process $[43,48]$. That is, the capacitance of the film mainly arises from the charge separation between the oxidised PPy backbone and the doping counteranions.

This result was supported by capacitance measurements performed using cyclic voltammetry. PPy-C4S films were grown to a range of charges and the resulting films were cycled at various scan rates between the potentials of 0.100 and $0.200 \mathrm{~V}$ vs. SCE. This narrow potential window was used in an effort to avoid any faradaic contributions to the current. The capacitance could then be obtained from the slope of a linear plot of current against scan rate (Inset of Figure 7b). It can be seen from Figure $7 b$ that the capacitance measured in this way increased linearly with electropolymerization charge. This observation was typical of PPy films and was again consistent with the capacitance of the film arising from the charge separation between oxidised sites along the polymer backbone and the anionic $\mathrm{C} 4 \mathrm{~S}$ dopant.

\section{Conclusions}

Polypyrrole films doped with $p$-sulfonatocalix[4]arene (C4S) were investigated primarily using the techniques of cyclic voltammetry, EQCM and electrochemical impedance spectroscopy. This allowed the systematic characterisation of both the redox and the ion exchange properties of the PPy-C4S film.

During the course of the cyclic voltammetry studies it became apparent that the calixarene in the polymer could be oxidised at similar potentials to those required for its oxidation in aqueous solution. As a result of this process, a new electroactive species was generated within the PPy$\mathrm{C} 4 \mathrm{~S}$ film giving rise to a quasi-reversible redox couple. We propose that this new species is a quinone. This process had implications for the stability of the film. In order to form a film which would be stable under potential cycling conditions the polymer had to be grown at a potential of $\leq 0.500 \mathrm{~V}$ vs. SCE. Moreover, if the polymer is cycled to potentials above $0.800 \mathrm{~V}$ vs. SCE the background current decays steadily indicating a loss in the conductivity of the polymer.

The results from the EQCM and impedance analysis indicate that the polymer acts as a cation ion exchange material, becoming doped and undoped by $\mathrm{Na}^{+}$ions during its redox switching. However, the exchange process is complicated by the transport of neutral species at the slower scan rates. In addition, the impedance data indicates that between the potentials of $-0.800 \mathrm{~V}$ and $0.500 \mathrm{~V}$ vs. SCE the PPy-C4S system acts like a typical polypyrrole film doped with an immobile anion. The significance of this result is that the complications associated with the electroactivity of the calixarene can be avoided within these potentials, giving a stable polymer modified electrode. It is likely that some of the features noted in the literature about these systems arise from the oxidation of the calixarene within the polymer. For example, while the PPy-C6S membrane system developed by Akieh et al. would only allow the passage of cations upon reduction, pulsing the membrane to positive potentials, thereby reoxidising the film, did not switch off the cation transport [20]. This is in contrast to the results obtained for related membranes based on PPy films doped with non redox active compounds such as PSS [49] and sulfonated $\beta$-cyclodextrin [50]. Consequently, we propose that it is only within the potential window of $-0.800-0.500 \mathrm{~V}$ 
vs SCE that the PPy-C4S film is suited for electrochemical sensing or redox active membrane applications.

\section{Acknowledgements}

This project is funded as part of the Science, Technology, Research and Innovation for the Environment (STRIVE) Programme 2007-2013. The programme is financed by the Irish Government under the National Development Plan 2007-2013 and it is administered on behalf of the DEHLG by the Environmental Protection Agency (EPA) which has the statutory function of coordinating and promoting environmental research. RD gratefully acknowledges the award of an Embark Initiative Irish Research Council for Science, Engineering and Technology (IRCSET) Ph.D Scholarship and a John \& Pat Hume scholarship from N.U.I. Maynooth. Additional funding was provided by the Science Foundation Ireland through the National Access Programme of the Tyndall National Institute, University College Cork.

\section{References}

[1] Z.-Y. Li, J.-W. Chen, Y. Liu, W. Xia, L. Wang, Curr. Org. Chem. 2011, 15, 39.

[2] B. Mokhtari, K. Pourabdollah, N. Dalali, Chromatographia 2011, 73, 829.

[3] B. Mokhtari, K. Pourabdollah, N. Dalali, J. Coord. Chem. 2011, 64,743 .

[4] L. Mutihac, Anal. Lett. 2010, 43, 1355.

[5] B. Mokhtari, K. Pourabdollah, N. Dallali, J. Radioanal. Nucl. Chem. 2011, 287, 921.

[6] D-S. Guo, K. Wang, Y. Liu, J. Inclusion Phenom. Macrocyclic Chem. 2008, 62, 1.

[7] O. Danylyuk, K. Suwinska, Chem. Commun. 2009, 5799.

[8] E. Karakhanov, T. Buchneva, A. Maximov, M. Zavertyaeva, J. Mol. Catal. A, Chem. 2002, 184, 11.

[9] D. Xiong, M. Chen, H. Li, Chem. Commun. 2008, 880.

[10] J. M. Davey, C. O. Too, S. F. Ralph, L. A. P. Kane-Maguire, G. G. Wallace, A. C. Partridge, Macromolecules 2000, 33, 7044.

[11] Z. Mousavi, J. Bobacka, A. Ivaska, Electroanalysis 2005, 17, 1609.

[12] G. Bidan, M.-A. Niel, Synth. Met. 1997, 84, 255.

[13] L. T. T. Kim, C. Gabrielli, A. Pailleret, H. Perrot, Electrochim. Acta 2011, 56, 3516.

[14] L. Zhang, A. Macias, T. Lu, J. I. Gordon, G. W. Gokel, A. E. Kaifer, Chem. Commun. 1993, 1017.

[15] K. Kaneto, G. Bidan, Thin Solid Films 1998, 331, 272.

[16] M. Vazquez, J. Bobacka, M. Luostarinen, K. Rissanen, A. Lewenstam, A. Ivaska, J. Solid State Electrochem. 2005, 9, 312.

[17] R. Doyle, C. B. Breslin, A. D. Rooney, Chem. Biochem. Eng. Q. 2009, 23, 93.
[18] C. Weidlich, K.-M. Mangold, Electrochim. Acta 2011, 56, 3481.

[19] M. N. Akieh, Á. Varga, R-M. Latonen, S. F. Ralph, J. Bobacka, A. Ivaska, Electrochim. Acta 2011, 56, 3507.

[20] M. N. Akieh, S. F. Ralph, J. Bobacka, A. Ivaska, J. Membr. Sci. 2010, 354, 162.

[21] A. Pailleret, N. Magan-Oliva, S. Ollivier, D. W. M. Arrigan, J. Electroanal. Chem. 2001, 508, 81.

[22] A. Pailleret, D. W. M. Arrigan, Langmuir 2002, 18, 9447.

[23] G. Diao, W. Zhou, J. Electroanal. Chem. 2004, 567, 325.

[24] G. Diao Y. Liu, Electroanalysis 2005, 17, 1279.

[25] M. Chen, H.-L. Wang, J. Gu, G.-W. Diao, J. Appl. Electrochem. 2007, 37, 331.

[26] A. Louati, J. Spraula, V. Gabelica, P. Kuhn, D. Matt, Electrochem. Commun. 2006, 8, 761.

[27] T. D. Chung, H. Kim, J. Inclusion Phenom. Macrocyclic Chem. 1998, 32, 179.

[28] S. Shinkai, K. Araki, T. Tsubaki, T. Arimura, O. Manabe, $J$. Chem. Soc. Perkin Trans. 1 1987, 11, 2297.

[29] R. L. Zhu, G. X. Li, J. H. Zheng, J. W. Jiang, H. B. Zeng, Surf. Eng. 2009, 25, 156.

[30] J. I. Reyes De Corcuera, R. P. Cavalieri, J. R. Powers, Synth. Met. 2004, 142, 71.

[31] K. R. Ansari, Russ. J. Electrochem. 2005, 41, 950.

[32] T. Raudsepp, M. Marandi, T. Tamm, V. Sammelselg, J. Tamm, Electrochim. Acta 2008, 53, 3828.

[33] C. K. Baker, Y. J. Qiu, J. R. Reynolds, J. Phys. Chem. 1991, 95, 4446.

[34] J.-B. Raoof, R. Ojani, S. Rashid-Nadimi, Electrochim. Acta 2004, 49, 271.

[35] R. Vataj, A. Louati, C. Jeunesse, D. Matt, Electrochem. Commun. 2000, 2, 769.

[36] A. Ronlan, J. Chem. Soc. Chem. Commun. 1971, 24, 1643.

[37] R. Doyle, PhD Thesis, NUI Maynooth, 2011.

[38] C. C. Harley, A. D. Rooney, C. B. Breslin, Sens. Actuators B 2010, B150, 498.

[39] M. N. Akieh, W. E. Price, J. Bobacka, A. Ivaska, S. F. Ralph, Synth. Met. 2009, 159, 2590.

[40] K. Naoi, M. Lien, W. H. Smyrl, J. Electrochem. Soc. 1991, $138,440$.

[41] R. M. Torresi, S. I. Cordoba de Torresi, T. Matencio, M. A. De Paoli, Synth. Met. 1995, 72, 283.

[42] S. Bruckenstein, A. R. Hillman, J. Phys. Chem. 1988, 92, 4837.

[43] W. J. Albery, Z. Chen, B. R. Horrocks, A. R. Mount, P. J. Wilson, D. Bloor, A. T. Monkman, C. M. Elliott, Faraday Discuss. Chem. Soc. 1989, 88, 247.

[44] W. J. Albery, A. R. Mount, J. Chem. Soc. Faraday Trans. 1994, 90, 1115.

[45] J. F. Rubinson, Y. P. Kayinamura, Chem. Soc. Rev. 2009, 38, 3339.

[46] X. Ren, P. G. Pickup, J. Electroanal. Chem. 1997, 420, 251.

[47] X. Ren, P. G. Pickup, J. Phys. Chem. 1993, 97, 5356.

[48] M. Grzeszczuk, G. Zabinska-Olszak, J. Electroanal. Chem. 1997, 427, 169.

[49] C. Weidlich, K.-M. Mangold, K. Jüttner, Electrochim. Acta 2005, 50, 5247.

[50] D. A. Reece, S. F. Ralph, G. G. Wallace, J. Membr. Sci. 2005, 249,9 . 